\title{
ON LINEAR ANISOTROPIC ELASTICITY DAMAGE TENSOR
}

Jovo Jarić ${ }^{1}$

Dragoslav Kuzmanović ${ }^{2}$

UDK: 514.743 .4

DOI:10.14415/konferencijaGFS2017.027

Summary: In this paper, the anisotropic linear damage mechanics is presented starting from the principle of strain equivalence. In (Jarić et al. (2013)) damage tensor components are derived in terms of elastic parameters of undamaged (virgin) material in closed form solution. Here, making use of this paper, we derived elasticity tensor as a function of damage tensor also in closed form. The procedure we present here was applied for several crystal classes which are subjected to hexagonal, orthotropic, tetragonal, cubic and isotropic damage. As an example isotropic system is considered in order to present some possibility to evaluate its damage parameters.

Keywords: Damage tensor, Symmetry group, Anisotropy crystal classes, Isotropic system, Damage parameters, Elastic wave.

\section{INTRODUCTION}

In order to make this contribution self-sufficient we present the main ideas of the principles of strain equivalence used by [3].

The effective stress $\tilde{\boldsymbol{\sigma}}$ is the stress tensor to be applied to a virgin representative volume element in order to obtain the same elastic strain tensor, $\boldsymbol{\varepsilon}^{e}$, produced by applying the actual stress tensor $\boldsymbol{\sigma}$, to the damage volume element. Because the same elastic strain is considered in both damaged and undamaged materials, that strain is considered to be the equivalent strain.

By definition, often called the principle of strain equivalence, the actual stress and effective stress satisfy the equations:

$$
\begin{aligned}
\sigma_{i j} & =\mathbb{C}_{i j k l} \varepsilon_{k l}^{e}, \\
\tilde{\sigma}_{i j} & =\mathbb{E}_{i j k l} \varepsilon_{k l}^{e},
\end{aligned}
$$

\footnotetext{
${ }^{1}$ Jovo Jarić, University of Belgrade, Faculty of Mathematics, Serbia, e - mail: jovojaric@ yahoo.com ${ }^{2}$ Dragoslav Kuzmanović, University of Belgrade, Faculty of Transport and Traffic Engineering, Serbia, e mail: d.kuzmanovic@sf.bg.ac.rs
} 
where

$\mathbb{E}_{i j k l}$ - is elastic modulus tensor of the virgin material,

$\mathbb{C}_{i j k l}$ - is elasticity tensor of the damage material.

In the virgin state, even in the most general case of anisotropy, there are only 21 independent elements of the fourth-order elastic modulus tensor $\mathbb{E}$. The symmetry of $\mathbb{E}$, applied to $\mathbb{C}$ as well, and dictates a maximum of 21 independent elements.

Following [1] it can be shown that

$$
\sigma_{i j}=\mathbb{R}_{i j k l} \tilde{\sigma}_{k l}
$$

where the fourth-order tensor $\mathbb{R}$ possess symmetry in successive pairs of indices.

It can be shown that $\mathbb{R}$ can be written in the form

$$
\mathbb{R}=\mathbb{I}-\mathbb{D},
$$

where $\mathbb{I}$ is the unit tensor. The forth-order tensor $\mathbb{D}$ is known as damage tensor.

From Equations (1)-(4) [1] obtained

$$
\mathbb{C}=\mathbb{E}-\mathbb{D E} .
$$

Obviously, the number of independent elements of tensor $\mathbb{D}$ and their values are determined by the value of tensors $\mathbb{E}$ and $\mathbb{C}$. We investigate that assuming that $\mathbb{E}$ is always given, and considering Equation (5) as a linear equation with respect to $\mathbb{C}$ and $\mathbb{D}$. Then, in order to determine, or equivalently to find the solution of (5), one of them has to be known.

First. Assume that we want to find $\mathbb{C}$ for given $\mathbb{D}$. Then $\mathbb{D}$ cannot be given arbitrary in order to find $\mathbb{C}$ since we assume that $\mathbb{C}$ posses major symmetry. In that case $\mathbb{D}$ must satisfies conditions

$$
\mathbb{D} \mathbb{E}=\mathbb{E} \mathbb{D}^{T} \text {. }
$$

Second. We consider that $\mathbb{E}, \mathbb{C}$ are given and we want to find tensor $\mathbb{D}$. Since $\mathbb{E}$ is positive definite there is always $\mathbb{E}^{-1}$ such that $\mathbb{E} \mathbb{E}^{-1}=\mathbb{I}$. Thus

$$
\mathbb{D}=\mathbb{I}-\mathbb{C E}^{-1} \text {. }
$$

Proposition 1 Damage tensor $\mathbb{D}$, given by Equation (7), always satisfies the constrain Equation (6).

Proposition 2 The corresponding isotropy groups of tensors $\mathbb{C}$ and $\mathbb{D}$ are the same ([6]).

\section{ELASTICITY TENSOR OF DAMAGE}

Here, we present the results of our procedure for two crystal classes. 
Contemporary achievements in civil engineering 21. April 2017. Subotica, SERBIA

\subsection{HEXAGONAL ELASTICITY DAMAGE TENSOR}

In this case

$$
\begin{aligned}
\mathbb{D}_{i j k l} & =d_{1} \delta_{i j} \delta_{k l}+d_{2}\left(\delta_{i k} \delta_{j l}+\delta_{i l} \delta_{j k}\right)+d_{3} n_{3 i} n_{3 j} n_{3 k} n_{3 l}+ \\
& +d_{4}\left(n_{3 i} n_{3 j} \delta_{k l}+n_{3 k} n_{3 l} \delta_{i j}\right)+ \\
& +d_{5}\left(n_{3 i} n_{3 k} \delta_{j l}+n_{3 j} n_{3 l} \delta_{i k}+n_{3 i} n_{3 l} \delta_{j k}+n_{3 j} n_{3 k} \delta_{i l}\right)+ \\
& +d_{6} n_{3 i} n_{3 j} \delta_{k l} . \\
\mathbb{C}_{i j k l} & =\left[\lambda\left(1-3 d_{1}-2 d_{2}-d_{4}\right)-2 \mu\right] \delta_{i j} \delta_{k l}+ \\
& +\mu\left(1-2 d_{2}\right)\left(\delta_{i k} \delta_{j l}+\delta_{i l} \delta_{j k}\right)- \\
& -\left[\lambda\left(d_{3}+3 d_{4}+4 d_{5}+3 d_{6}\right)+2 \mu d_{6}\right] n_{3 i} n_{3 j} \delta_{k l}- \\
& -2 \mu d_{3} n_{3 i} n_{3 j} n_{3 k} n_{3 l}-2 \mu d_{4}\left(n_{3 i} n_{3 j} \delta_{k l}+n_{3 k} n_{3 l} \delta_{i j}\right)- \\
& -2 \mu d_{5}\left(n_{3 i} n_{3 k} \delta_{j l}+n_{3 j} n_{3 l} \delta_{i k}+n_{3 i} n_{3 l} \delta_{j k}+n_{3 j} n_{3 k} \delta_{i l}\right),
\end{aligned}
$$

so that

$$
\begin{aligned}
& \lambda_{1}=\lambda\left(1-3 d_{1}-2 d_{2}-d_{4}\right)-2 \mu d_{1} \\
& \lambda_{2}=\mu\left(1-2 d_{2}\right) \\
& \lambda_{3}=-2 \mu d_{3} \\
& \lambda_{4}=-2 \mu d_{4} \\
& \lambda_{5}=-2 \mu d_{5},
\end{aligned}
$$

and

$$
\lambda\left(d_{3}+3 d_{4}+4 d_{5}+3 d_{6}\right)+2 \mu d_{6}=0 .
$$

\subsection{ISOTROPIC DAMAGE}

This is the simplest case. Then

$$
\mathbb{C}_{i j k l}=\lambda_{1} \delta_{i j} \delta_{k l}+\lambda_{2}\left(\delta_{i k} \delta_{j l}+\delta_{i l} \delta_{j k}\right)
$$

where

$$
\begin{aligned}
& \lambda_{1}=\lambda\left(1-3 d_{1}-2 d_{2}\right)-2 \mu d_{1}, \\
& \lambda_{2}=\mu\left(1-2 d_{2}\right) .
\end{aligned}
$$

\section{SOME POSSIBILITIES WAY TO EVALUATE DAMAGE PARAMETERS OF ISOTROPIC DAMAGE}

There remains also the quantitative evaluation of damage parameters from actual tests. This is an endeavor that can be done by the present work by means of the physically meaningful damage parameters that are given in terms of the basic elements of $\mathbb{D}$. 
We shell demonstrate it for isotropic systems. It is known (see [11], p. 550, eq.(8.4.10)), for other crystal systems see [12] that the velocities of wave propagation for isotropic elastic material (undamage material) have the following expressions

$$
\begin{array}{ll}
v_{L}=\left(\frac{\lambda+2 \mu}{\rho}\right)^{1 / 2}, & \text { - longitudinal velocity } \\
v_{T}=\left(\frac{\mu}{\rho}\right)^{1 / 2}, & \text { - transversal velocity. }
\end{array}
$$

We now apply it to isotropic damage materials. In this case the corresponding quantities are

$$
\begin{aligned}
& \lambda \rightarrow \lambda_{1}=\lambda\left(1-3 d_{1}-2 d_{2}\right)-2 \mu d_{1}=\rho_{d}\left(v_{d L}^{2}-2 v_{d T}^{2}\right), \\
& \mu \rightarrow \lambda_{2}=\mu\left(1-2 d_{2}\right)=\rho_{d} v_{d T}^{2} .
\end{aligned}
$$

Also, we denoted by subindex $d$ corresponding density and velocities of isotropic damage materials, i.e.

$$
\rho \rightarrow \rho_{d}, \quad v_{L} \rightarrow v_{d L}, \quad v_{T} \rightarrow v_{d T} .
$$

Then

$$
\lambda_{1}=\rho_{d}\left(v_{d L}^{2}-2 v_{d T}^{2}\right), \quad \lambda_{2}=\rho_{d} v_{d T}^{2}
$$

and hence

$$
d_{1}=\frac{\rho_{d}}{3 \lambda+2 \mu}\left(v_{d L}^{2}-\frac{\lambda+2 \mu}{\mu} v_{d T}^{2}\right), \quad d_{2}=\frac{1}{2}\left(1-\frac{\rho_{d}}{\mu} v_{d T}^{2}\right) .
$$

In principle, the same approach can be applied to the other crystal classes.

It is also possible to estimate values of damage parameters $d_{1}$ and $d_{2}$ making use of the expression for Poasson's ratio $v$ in classical linear elasticity, i.e.

$$
v=\frac{\lambda}{2(\lambda+\mu)}
$$

(see [11] p.294, (6.2.41)). Then

$$
-1<v<1 / 2 .
$$

As the above, identifying the corresponding quantities for linear isotropic damage materials, we have

$$
v \rightarrow v_{d}=\frac{\lambda_{1}}{2\left(\lambda_{1}+\lambda_{2}\right)}, \quad \text { and } \quad-1<v_{d}=\frac{\lambda_{1}}{2\left(\lambda_{1}+\lambda_{2}\right)}<1 / 2 .
$$

Further,

$$
\lambda_{1}+\lambda_{2}=\lambda-(3 \lambda+2 \mu) d_{1}-2 \lambda d_{2}
$$




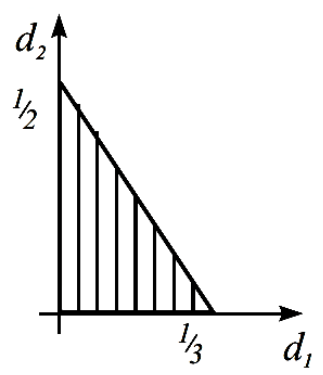

Figure 1:

The above inequality is satisfied when

$$
\begin{array}{ccc}
2 \lambda_{1}<2\left(\lambda_{1}+\lambda_{2}\right) & \Rightarrow \quad & \lambda_{2}>0, \\
\lambda_{2}=\mu\left(1-2 d_{2}\right)>0 & \Rightarrow \quad d_{2}<\frac{1}{2}
\end{array}
$$

and

$$
\begin{gathered}
-2\left(\lambda_{1}+\lambda_{2}\right)<\lambda_{1} \Rightarrow 3 \lambda_{1}+2 \lambda_{2}>0, \\
3 \lambda_{1}+2 \lambda_{3}=3 \lambda\left(1-3 d_{1}-2 d_{2}\right)+2 \mu\left(1-3 d_{1}-2_{2}\right)>0, \\
3 d_{1}+2 d_{2}<1 .
\end{gathered}
$$

The graph of these two inequalities

$$
d_{2}<\frac{1}{2} \quad 3 d_{1}+2 d_{2}<1
$$

is given in Fig. 1 .

In Fig. 1 the region of possible values of parameters $d_{1}$ and $d_{2}$ is given, i.e.

$$
0 \leq d_{1}<1 / 3, \quad 0<d_{2}<1 / 2 .
$$

\section{CONCLUDING REMARKS}

In the present paper the anisotropic elasticity damage mechanics is investigated within the framework of the classical theory of elasticity.

Starting from the principle of strain equivalence, elasticity tensor components are derived in terms of damage parameters in close forme.

The procedure we present here was applied for several crystal classes which are subjected to hexagonal, orthotropic, tetragonal, cubic and isotropic damage. We underline that this procedure can be applied for all crystal systems.

Finally, we propose some possibilities way to determined damage parameters of isotropic damage, and evaluate them. 


\section{REFERENCES}

[1] Cauvin, A., and Testa, R. (1999) Damage mechanics: Basic variables in continuum theories, International Journal of Solids and Structures, 36(5): 747-761.

[2] Chow, C. and Wang, J. (1987) An Anisotropic Theory of Elasticity for Continuum Damage Mechanics, Int. J. Fract., 33: 3-16.

[3] Cordebois, J. and Sidoroff, F. (1979) Damage Induced Elastic Anisotropy, Colloque Euromech, 115, Villard de Lans.

[4] Cowin, C.S., (2013) Continuum Mechanics of Anisotropic Materials, Berlin, Springer-Verlag.

[5] Frémond Michel (2002) Non-Smooth Thermomechanics, Springer.

[6] Gurtin, M.E. (1972) The linear theory of elasticity, Handbuch der Physik, 6a 2 , Berlin, Springer-Verlag.

[7] Jarić, J.P., Kuzmanović, D.S., and Šumarac, (2013) On Anisotropic Elasticity Damage Mechanics, International Journal of Damage Mechanics, 18(4): 371-392.

[8] Ju, J.W. (1990) Isotropic and Anisotropic Damage Variables in Continuum Damage Mechanics, Journal of Engineering Mechanics, 116(12): 2764-2770.

[9] Lemaitre J., Chaboche, J.-L. (1990) Mechanics of Solid Materials, Cambridge University Press.

[10] Lemaitre Jean. (1992). A Course on Damage Mechanics, Springer-Verlag, Berlin, Heidelberg, New York, London, Paris, Tokyo, Hong Kong, Barcelona, Budapest.

[11] Malvern, L.E.,(1969) Introduction to the Mechanics of a Continuos Mediun, PrenticeHall, Inc.

[12] Slawinski A. Michael (2010) Waves and rays in elastic continua, World Scientific Publishing Co. Pte. Ltd.

[13] Voyiadjis, G.Z., Yousef, M.A. and Kattan, P.I. (2012) New Tensors for Anisotropic Damage in Continuum Damage Mechanics, Journal of Engineering Materials and Tehnology, ASME, 134(2).

\section{O LINEARNOM ANIZOTROPNOM ELASTIČNOM TENZORU OŠTEĆENJA}

Rezime: U ovom radu linearna mehanika anizotropnog oštećenja je prezentirana koristeći princip ekvivalentnosti deformacije. U radu (Jarić $i$ dr., 2013) komponente tenzora oštećenja su izvedene u članovima parametara neoštećenog materijala u zatvorenom obliku. Postupak, koji je prezentiran u ovom radu, može da se primeni za različite kristalne klase koje su podvrgnute heksagonalnom, ortotropnom, tetragonalnom, kubnom $i$ izotropnom oštećenju. Kao poseban primer razmatran je izotropan sistem u cilju mogućeg određivanja parametara oštećenja.

Ključne reči: Tenzor oštećenja, Grupe simetrija, Anizotropne kristalne klase, Izotropni sistem, Parametri oštećenja, Elastični talasi. 